\title{
REACTIVITY OF MONOCLONAL ANTIBODIES DIRECTED AGAINST LUNG CANCER ANTIGENS WITH HUMAN LUNG, BREAST AND COLON CANCER CELL LINES
}

\author{
UDO SCHUMACHER*, DHIA MUKTHAR*, THOMAS SCHENKER** \\ * Human Morphology, University of Southampton, Southampton, U.K. \\ ** Division of Oncology, University Hospital Zürich, Zürich, Switzerland.
}

\begin{abstract}
SUMMARY
A panel of monoclonal antibodies ( $\mathrm{n}=72$ including controls) directed against lung cancer antigens was screened immunohistochemically against a panel of seven human lung cancer cell lines (including small cell carcinoma, squamous cell carcinoma, adenocarcinoma and mesothelioma), six human breast cancer cell lines and one human colon cancer cell line. The majority of the antibodies $(n=42)$ reacted also with antigens present on breast and colon cancer cell lines. This cross reactivity especially between lung and breast cancer cell lines is not altogether unexpected since antigens common to breast and lung tissue including their neoplasms such as MUC1 antigen have been described. Our results indicate that epitopes shared by lung and breast cancers are probably more common than previously thought. The relevance for prognosis and therapy of these shared antigens, especially as disease markers in breast cancer, has to be investigated.
\end{abstract}

KEY WORDS Lung cancer Monoclonal antibodies Reactivity

\section{INTRODUCTION}

Some antigens common to lung and breast epithelia can be classified as oncodevelopmental. One of these, the MUC1 antigen, detected during development in lung, mammary gland and other tissues of epithelial origin (Braga et al., 1992), is conserved during evolution (Welsch et al., 1990, Spicer et al., 1991, Pemberton et al., 1992) and the antigen can be recovered from the human broncho-alveolar-lavage (Schumacher et al., 1989).

Since mucin antigens which are expressed in lung and mammary gland have been described, the monoclonal antibody panel (submitted to the panel of the third international association for the study of lung cancer [IASLC] workshop on lung tumour and differentiation antigens) was tested for cross reactivity with human breast cancer cell lines. In addition serving as a further control, a human colon cancer cell line was included in the test panel of cell lines.

Correspondence to: Udo Schumacher, Human Morphology, University of Southampton, Bassett Crescent East, Southampton SO9 3TU, U. K. Tel: (+)44-703-594231; Fax: (+)44-703-594433. 


\section{MATERIALS AND METHODS}

Human breast cancer cell lines (MCF7, BT-549, T47D, HBL100, MDA-MB-157, HS578T) and the human colon cancer cell line HT29 were obtained from the European Cell Culture Collection (Porton Down, Salisbury, Wiltshire, UK) and maintained under the standard culture conditions supplied with the data sheets for each cell line. The human lung cancer cell lines $\mathrm{N}-417$ (derived from small cell carcinoma, variant, kindly provided by Dr. D. N. Carney, Mater Misericordiae Hospital, Dublin, Ireland), SW2 (classic, kindly provided by Dr. S. Bernal, Boston, USA), ZL5 and ZL34 (from mesothelioma, generated in Zürich), U1752 (from squamous cell carcinoma, kindly provided by Dr. J. Berh, Uppsala, Sweden) and A125 (from adenocarcinoma, obtained from American Type Culture Collection, Rockville, Maryland) were cultured in RPMI-1640 medium supplemented with $2 \mathrm{mMol} / \mathrm{l} \mathrm{L-glutamine}$ and $10 \%$ fetal calf serum. The immortalised human bronchial epithelial-derived cell line (BEAS-2B, kindly provided by Dr. C. Harris, Bethesda, Maryland) was cultured in Hams F12 based medium supplemented with $5 \mathrm{mg} / \mathrm{L}$ insulin, $5 \mathrm{mg} / \mathrm{L}$ transferrin, $70 \mathrm{ug} / \mathrm{L}$ hydrocortisone, $0.1 \mathrm{mg} / \mathrm{L}$ vitamin $\mathrm{A}$, $650 \mathrm{ug} / \mathrm{L}$ triiodo-L-thyronine, $2 \mathrm{mg} / \mathrm{L}$ epinephrine, $30 \mathrm{mg} / \mathrm{L}$ bovine pituitary extract, $50 \mathrm{mg} / \mathrm{L}$ bovine serum albumin, $5 \mathrm{ug} / \mathrm{L}$ purified mouse epidermal growth factor, $5 \mathrm{uM} / \mathrm{L}$ ethanolamine and $50 \mathrm{mg} / \mathrm{L}$ gentamycin.

For the immunofluorescence assay the breast and colon cancer cell lines were grown to confluence on coverslips and briefly fixed in cold methanol. The cells were incubated with the antibody panel (Table 1) including the positive and negative control reagents and the anti mouse or rat FITC-labelled antibodies were used for visualisation. The fluorescence intensity was evaluated semi-quantitatively: - = no fluorescence, $(+)=$ very weak fluorescence, $+=$ weak fluorescence, $++=$ modest fluorescence, $+++=$ intense fluorescence, $++++=$ very intense fluorescence. The intensity measurements of the lung cancer cell lines were obtained by FACS; the results of the FACS analyses were transformed into the above scale.

\section{RESULTS}

The details of the results of this study are summarised in Table 2 and can be classified into four groups: 1) those antibodies which did not react with any of the cell lines ( $\mathrm{n}=$ 14 , including the negative controls), 2) those which reacted with breast and colon cancer cell lines only $(n=11), 3)$ those which reacted with lung cancer cell lines only $(n=17)$ and 4$)$ those which reacted with breast, colon and lung cancer cell lines $(n=30)$. Amongst groups two to four the numbers of reactive antibodies and the intensity of fluorescence varied considerably. In some cases antibodies reacted only with one cell line (e. g. the antibody number 16 reacted with the cell line T47D only), while other antibodies showed a broader reactivity (antibody number 50 reacted with all the cell lines except two breast cancer cell lines MDA-MB-157 and HBL 100). Differences in fluorescence intensity were detected not only between the different cell lines but also between cells of the same cell line (e. g. only $40 \%$ of the cells from the cell line BT 549 showed strong reactivity with antibodies number $35 \& 36$ ). In other cases some antibodies reacted with all cells of a particular cell line (Fig. 1) while other antibodies reacted only with some cells of that cell line (Fig. 2). 
Table 1. List of antibodies used in the present study

\begin{tabular}{|c|c|c|c|c|c|}
\hline No & Name & Isotype & Submitter & Antigen & Publications \\
\hline 1 & $44-3$ A6 & IgG1 & Radosevich & $40 \mathrm{kd}$ cell surface & $\begin{array}{l}\text { Tumor Biol., } 9 \text { (2-3), } \\
116-22(1988) \text { and } 11 \\
(4), 181-188(1990)\end{array}$ \\
\hline 2 & EMD6087 & IgG1 & E. Merck & $45+85 \mathrm{kd} g \mathrm{p}$ & $\begin{array}{l}\text { Cancer Res., 46, } \\
\text { 6369-6373 (1986) }\end{array}$ \\
\hline 3 & EMD5590 & $\operatorname{IgG} 2 \mathrm{a}$ & E.Merck & EGF receptor & $\begin{array}{l}\text { Arch. Biochem. } \\
\text { Biophys., 252, 549-560 } \\
\text { (1987) }\end{array}$ \\
\hline 4 & ITK2 & IgG1 & Kawase & NCAM & $\begin{array}{l}\text { Cancer Immunol. } \\
\text { Immunother., 33, } \\
165-170(1991)\end{array}$ \\
\hline 5 & KM195 & IgG1 & Hanai & $\mathrm{n} / \mathrm{a}$ & \\
\hline 6 & RS7-3G11 & IgG1 & Stein & EGP-1/GA733-1 & $\begin{array}{l}\text { Antibody, } \\
\text { Immunoconjugates and } \\
\text { Radiopharm., } \mathbf{4}, \\
\text { 703-712(1991), Mol. } \\
\text { cell. Biol., 13, } \\
\text { 1507-1515 (1993), see } \\
\text { also No. } 7 .\end{array}$ \\
\hline 7 & RS5-4H6 & IgG1 & Stein & $>300 \mathrm{kd}$, mucinlike & $\begin{array}{l}\text { Cancer Res.,50, } \\
1330-1336(1990) \text { and } \\
\text { Hybridoma, 7, 555-567 } \\
(1988)\end{array}$ \\
\hline 8 & A42 & $\operatorname{IgG} 2 b$ & Mattes & $57 \mathrm{kd} \mathrm{gp}$ & $\begin{array}{l}\text { J. Exp. Med., 164, } \\
1581-1599(1986)\end{array}$ \\
\hline 9 & MR54 & $\operatorname{IgG} 2 \mathrm{a}$ & Mattes & $\mathrm{n} / \mathrm{a}$ & $\mathrm{n} / \mathrm{a}$ \\
\hline 10 & MT179 & IgG1 & Mattes & $\mathrm{n} / \mathrm{a}$ & $\begin{array}{l}\text { Cancer Res., 47, } \\
6741-6750 \text { (1987) }\end{array}$ \\
\hline 11 & MU78 & $\operatorname{IgG} 2 b$ & Mattes & $2-5 \mathrm{kd}$ & $\begin{array}{l}\text { J. Histochem. } \\
\text { Cytochem., } 33, \\
1095-1102(1985)\end{array}$ \\
\hline 12 & MW207 & IgG1 & Mattes & $\mathrm{n} / \mathrm{a}$ & see No 10 \\
\hline 13 & MX35 & IgG1 & Mattes & $\mathrm{n} / \mathrm{a}$ & see No 10 \\
\hline 14 & MAB735 & $\operatorname{IgG} 2 \mathrm{a}$ & Behring-werk & embryonic NCAM & $\begin{array}{l}\text { Proc. Natl. Acad. Sci. } \\
\text { U.S.A., 82, 1194-1198 } \\
\text { (1985) and J. Pathol., } \\
\text { 159, 23-28 (1989) }\end{array}$ \\
\hline 15 & RCK-107 & IgG1 & Broers & keratin 14 & $\begin{array}{l}\text { Am. J. Pathol., 138, } \\
751-763 \text { (1991) }\end{array}$ \\
\hline 16 & RCK-105 & IgG1 & Broers & keratin 7 & $\begin{array}{l}\text { see No } 15 \text { and Experi- } \\
\text { mental Cell Res., 170, } \\
\text { 235-249 (1987) }\end{array}$ \\
\hline 17 & RNL-2 & IgG1 & Broers & $25+45 \mathrm{kd}$, intracell. & $\begin{array}{l}\text { Cancer, 67, 619-633 } \\
\text { (1991) }\end{array}$ \\
\hline 18 & RNL-3 & IgG1 & Broers & $25+45 \mathrm{kd}$, intracell. & see No 17 \\
\hline 19 & RNL-1 & IgG1 & Broers & NCAM & see No 17 \\
\hline
\end{tabular}




\begin{tabular}{|c|c|c|c|c|c|}
\hline 20 & MLuC-6 & $\operatorname{IgG1}$ & Menard & $\begin{array}{l}67 \mathrm{kd} \text { Laminin } \\
\text { receptor }\end{array}$ & $\begin{array}{l}\text { Clin. Exp. Metastasis, } \\
\mathbf{1 0}, 379-386\end{array}$ \\
\hline 21 & MAR-4 & IgG1 & Menard & ${ }_{1}$ Integrin & Tumori, 78, 1-4 (1992) \\
\hline 22 & MAR-6 & IgG1 & Menard & 64 Integrin & $\begin{array}{l}\text { Int. J. Cancer, 54, 261- } \\
267 \text { (1993) }\end{array}$ \\
\hline 23 & MLuC-1 & $\operatorname{IgG} 20.3$ & Menard & Le $^{y}$ hapten & $\begin{array}{l}\text { Int. J. Cancer, 51, 225- } \\
231 \text { (1992) }\end{array}$ \\
\hline 24 & MB-2 & IgG1 & $\begin{array}{l}\text { Gerardy- } \\
\text { Schahn }\end{array}$ & NCAM & submitted \\
\hline 25 & KD-11 & IgG1 & $\begin{array}{l}\text { Gerardy- } \\
\text { Schahn }\end{array}$ & $\begin{array}{l}\text { NCAM, C-term., } \\
\text { intracellular }\end{array}$ & submitted \\
\hline 26 & MG-5 & $\operatorname{IgG} 1$ & $\begin{array}{l}\text { Gerardy- } \\
\text { Schahn }\end{array}$ & $\begin{array}{l}\text { NCAM, exon } 18 \text {, } \\
\text { intracellular }\end{array}$ & submitted \\
\hline 27 & MOC-31 & IgG1 & De Leij & $\begin{array}{l}\text { cluster } 2 \text { control, } \\
\text { EGP-2/GA733-2 }\end{array}$ & $\begin{array}{l}\text { Br. J. Cancer, 67, } \\
\text { 1242-1247 (1993) }\end{array}$ \\
\hline 28 & ME-1 & IgG1 & Stahel & $\begin{array}{l}\text { mesothelial } \\
\text { membrane antigen }\end{array}$ & $\begin{array}{l}\text { Int. J. Cancer, 41, } \\
218-223(1988) \text { and Am. } \\
\text { J. Pathol., 136, 421-428 } \\
\text { (1990) }\end{array}$ \\
\hline 29 & SEN36 & IgG1 & Stahel & NCAM & $\begin{array}{l}\text { Br. J. Cancer, 63, Suppl. } \\
\text { XIV, 24-28 (1991) }\end{array}$ \\
\hline 30 & SWA11 & $\operatorname{IgG} 2 \mathrm{a}$ & Stahel & $\begin{array}{l}\text { cluster w4 control, } \\
\text { CD24 }\end{array}$ & $\begin{array}{l}\text { Cancer Res., 52, } \\
\text { 5264-5270 (1992), Int. } \\
\text { J. Cancer, 53, 521-528 } \\
\text { (1993) and Clin. Exp. } \\
\text { Immunol., 93, 279-285 } \\
\text { (1993) }\end{array}$ \\
\hline 31 & SEN31 & IgG1 & Stahel & cluster 5 a control & $\begin{array}{l}\text { Br. J. Cancer, 63, Suppl. } \\
\text { XIV, 29-32 and 67-70 } \\
\text { (1991) }\end{array}$ \\
\hline 32 & SEN7 & IgG1 & Stahel & NCAM & $\begin{array}{l}\text { Cancer Res., 53, } \\
2840-2845 \text { (1993) }\end{array}$ \\
\hline 33 & MON-114 & IgG1 & Van de Ven & $\mathrm{n} / \mathrm{a}$ & $\mathrm{n} / \mathrm{a}$ \\
\hline 34 & MON-150 & IgG1 & Van de Ven & $\mathrm{n} / \mathrm{a}$ & $\mathrm{n} / \mathrm{a}$ \\
\hline 35 & KL-6 & IgG1 & Kohno & mucin-like sial.gp & $\begin{array}{l}\text { Jpn. J. Clin. Oncol., 18, } \\
\text { 203-216, (1988) and } \\
\text { Chest, 96, 68-73 (1989) }\end{array}$ \\
\hline 36 & OE-130 & IgG1 & Hida & $130 \mathrm{kd}$ & $\begin{array}{l}\text { Cancer Res., 48, } \\
2544-2549(1988)\end{array}$ \\
\hline 37 & FBP146 & IgG1 & Franklin & $\begin{array}{l}\text { folate binding } \\
\text { protein }\end{array}$ & $\begin{array}{l}\text { Am. J. Pathol., (1993), } \\
\text { submitted }\end{array}$ \\
\hline 38 & FBP343 & IgG1 & Franklin & $\begin{array}{l}\text { folate binding } \\
\text { protein }\end{array}$ & see No 37 \\
\hline 39 & FBP458 & IgG1 & Franklin & $\begin{array}{l}\text { folate binding } \\
\text { protein }\end{array}$ & see No 37 \\
\hline 40 & FBP741 & IgG1 & Franklin & $\begin{array}{l}\text { folate binding } \\
\text { protein }\end{array}$ & see No 37 \\
\hline 41 & ME-2 & $\mathrm{IgG} 2 \mathrm{~b}$ & Stahel & $\begin{array}{l}\text { mesothlial mem- } \\
\text { brane protein }\end{array}$ & see No 28 \\
\hline 42 & 2.54 & $\operatorname{IgG} 2 \mathrm{a}$ & Cole & $\begin{array}{l}22.5+25 \mathrm{kd} \\
\text { cellsurface }\end{array}$ & $\begin{array}{l}\text { Cancer Res., 49, 5719- } \\
5724(1989) \text { and Br. J. } \\
\text { Canc., 64, 15-22 (1991) }\end{array}$ \\
\hline
\end{tabular}




\begin{tabular}{|c|c|c|c|c|c|}
\hline 43 & BrE-3 & IgG1 & $\begin{array}{l}\text { Coulter } \\
\text { Immunology }\end{array}$ & mucin, MUC1 & $\begin{array}{l}\text { Int. J. Cancer, 52, } \\
\text { 624-630 (1992) }\end{array}$ \\
\hline 44 & KM432 & IgG1 & Hanai & & \\
\hline 45 & CC49 & IgG1 & Schlom & mucinlike, TAG-72 & $\begin{array}{l}\text { Cancer Res., 48, } \\
4588-4596 \text { and } \\
4597-03(1988)\end{array}$ \\
\hline 46 & B72.3 & IgG1 & Schlom & $\begin{array}{l}\text { mucinlike, } \\
\text { TAG-72 }\end{array}$ & see No 45 \\
\hline 47 & $\mathrm{CC} 83$ & IgG1 & Schlom & $\begin{array}{l}\text { mucinlike, } \\
\text { TAG-72 }\end{array}$ & see No 45 \\
\hline 48 & L6 & IgG1 & $\begin{array}{l}\text { Bristol-Myers } \\
\text { Squipp }\end{array}$ & $\begin{array}{l}24 \mathrm{kd} \\
\text { surfaceprotein }\end{array}$ & $\begin{array}{l}\text { Proc. Natl. Acad. Sci. } \\
\text { U.S.A., 89, 3503-3507 } \\
\text { (1992) }\end{array}$ \\
\hline 49 & not submitted & & & & \\
\hline 50 & СTM01 & IgG1 & Celltech Ltd. & $\begin{array}{l}\text { MUC } 1 \text { gene, } \\
\text { mucin }\end{array}$ & $\mathrm{n} / \mathrm{a}$ \\
\hline 51 & ABL364 & IgG1 & Sandoz & cluster w6 control & $\begin{array}{l}\text { Ann. Oncol., 3, 319-370 } \\
\text { (1992) }\end{array}$ \\
\hline 52 & MOPC21 & $\operatorname{IgG}$ & Sigma & mouse IgG control & $\mathrm{n} / \mathrm{a}$ \\
\hline 53 & PBS/azide & & & neg. control & \\
\hline 54 & 1.291 & IgM & Manderino & $\mathrm{n} / \mathrm{a}$ & $\mathrm{n} / \mathrm{a}$ \\
\hline 55 & 2.304 & $\operatorname{IgM}$ & Manderino & $\mathrm{n} / \mathrm{a}$ & $\mathrm{n} / \mathrm{a}$ \\
\hline 56 & A-80 & $\operatorname{IgM}$ & Manderino & cluster w8 control & $\mathrm{n} / \mathrm{a}$ \\
\hline 57 & KM227 & $\operatorname{IgM}$ & Hanai & $\mathrm{n} / \mathrm{a}$ & $\mathrm{n} / \mathrm{a}$ \\
\hline 58 & MG-6 & $\operatorname{IgM}$ & Koubek & $\mathrm{n} / \mathrm{a}$ & $\begin{array}{l}\text { Folia Haematol., 155, } \\
\text { 913-926 (1988) }\end{array}$ \\
\hline 59 & MLuC-5 & $\operatorname{IgM}$ & Menard & laminin receptor & see No 20 \\
\hline 60 & NCC-ST-439 & $\operatorname{IgM}$ & Shimosato & cluster w7 control & $\mathrm{n} / \mathrm{a}$ \\
\hline 61 & NCC-CO-450 & $\operatorname{IgM}$ & Shimosato & cluster w7 control & $\mathrm{n} / \mathrm{a}$ \\
\hline 62 & SCCL175 & $\operatorname{IgM}$ & Ball & $115+155 \mathrm{kd}$ & $\begin{array}{l}\text { Cancer Res., 48, } \\
\text { 7319-7322 (1988) }\end{array}$ \\
\hline 63 & KM132 & $\operatorname{IgM}$ & Hanai & $\mathrm{n} / \mathrm{a}$ & $\mathrm{n} / \mathrm{a}$ \\
\hline 64 & KM93 & $\operatorname{IgM}<$ & Hanai & sial. glycoprotein & $\begin{array}{l}\text { Cancer Res., 46, } \\
4438-4443(1986) \text { and } \\
\mathbf{4 7}, 1267-1272(1987)\end{array}$ \\
\hline 65 & CD57 & $\operatorname{IgM}$ & Serotec & NK cell antigen & $\mathrm{n} / \mathrm{a}$ \\
\hline 66 & TEPC1 83 & $\operatorname{IgM}$ & Sigma & mouse IgM control & $\mathrm{n} / \mathrm{a}$ \\
\hline 67 & PBS/azide & & & neg. control & \\
\hline 68 & KM966 & human IgG1 & Hanai & $\mathrm{n} / \mathrm{a}$ & $\mathrm{n} / \mathrm{a}$ \\
\hline 69 & AH41 & human IgG3 & $\begin{array}{l}\text { Boehringer } \\
\text { Mannheim }\end{array}$ & $\mathrm{n} / \mathrm{a}$ & $\mathrm{n} / \mathrm{a}$ \\
\hline 70 & KUB 10 & human IgG1 & $\begin{array}{l}\text { Boehringer } \\
\text { Mannheim }\end{array}$ & $\mathrm{n} / \mathrm{a}$ & $\mathrm{n} / \mathrm{a}$ \\
\hline 71 & ICR2 & rat IgG2a & $\begin{array}{l}\text { Wawrzyncak/ } \\
\text { Dean }\end{array}$ & mucin & $\begin{array}{l}\text { Histopathol., 16, } \\
\text { 573-581 (1990) }\end{array}$ \\
\hline 72 & ICR12 & rat IgG2a & $\begin{array}{l}\text { Wawrzyncak/ } \\
\text { Dean }\end{array}$ & $\begin{array}{l}\text { erbB-2 gene, } \\
\text { EGF receptor }\end{array}$ & $\begin{array}{l}\text { Int. J. Cancer, } \\
\mathbf{4 5}, 320-324 \text { (1990) }\end{array}$ \\
\hline
\end{tabular}

as provided by the submitter of the antibody $\mathrm{n} / \mathrm{a}=$ not available 




Fig. 1a

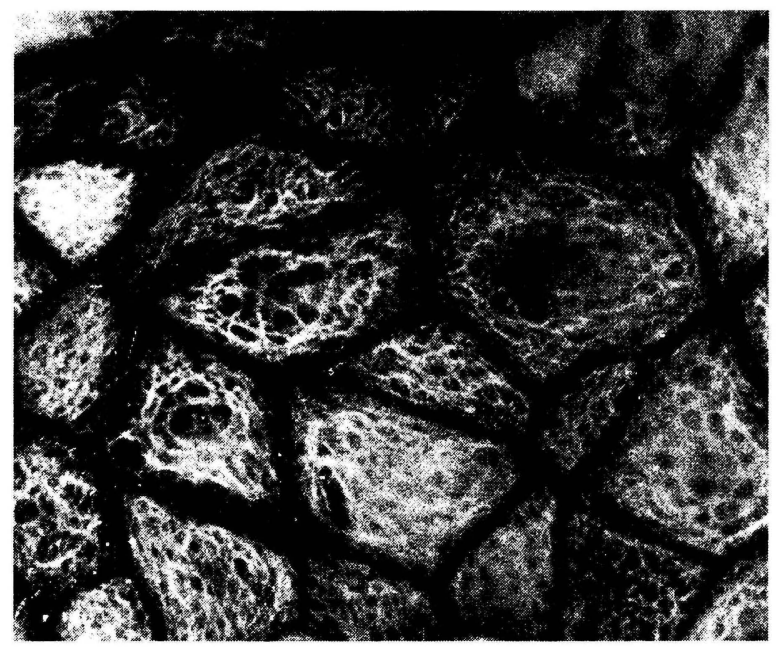

Fig. 1b

Figure 1. Photomicrographs showing FITC labelled cultured (a) HT29 colon cancer cell line and (b) MCF7 breast cancer cell line after reactivity with the antibody number 5 (KM195). X650.

The primary as well as the secondary anti-rat and anti-mouse antibodies were used at 1:50 dilutions and incubated with the cell preparations for 1 hour, both at room temperature. 
Table 2. Details of immunofluorescence reactivity.

\begin{tabular}{|c|c|c|c|c|c|c|c|c|c|c|c|c|c|c|}
\hline & BT549 & T47D & MCF7 & HT29 & MDAMB 157 & HBL100 & HS578T & N417 & SW2 & BEAS2B & ZL5 & ZL34 & U1752 & A125 \\
\hline 1 & - & - & $(+)$ & $(+)$ & - & - & - & - & - & - & - & - & - & - \\
\hline 2 & - & $\begin{array}{l}+ \\
\text { clones }\end{array}$ & - & - & - & - & - & ++++ & ++++ & ++++ & ++++ & ++++ & ++++ & $(+)$ \\
\hline 3 & - & - & - & - & - & - & - & $(+)$ & - & - & ++++ & ++++ & ++ & + \\
\hline 4 & + c.m. & - & - & - & - & - & - & ++++ & ++++ & - & - & $(+)$ & - & - \\
\hline 5 & - & +++ & ++++ & +++ & - & + c.m. & - & - & - & - & - & - & - & - \\
\hline 6 & - & - & - & - & - & - & - & - & - & ++++ & - & - & - & - \\
\hline 7 & - & $\begin{array}{l}+ \\
\text { clones }\end{array}$ & + rim & $(+)$ & - & - & - & - & + & + & - & ++ & + & + \\
\hline 8 & $(+30 \%)$ & - & - & $(+)$ & - & - & - & - & - & ++++ & ++++ & ++++ & - & ++++ \\
\hline 9 & - & - & - & $(+)$ & - & - & - & - & - & +++ & - & - & - & - \\
\hline 10 & $+/++$ & - & - & $(+)$ & - & - & - & - & - & $(+)$ & - & - & - & - \\
\hline 11 & - & - & - & $(+)$ & - & - & - & - & - & ++++ & ++++ & ++++ & $(+)$ & + \\
\hline 12 & - & $(+)$ & - & - & - & - & - & $(+)$ & - & - & & & & \\
\hline 13 & - & - & - & - & - & - & - & ++ & - & - & & . & $L$ & 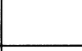 \\
\hline 14 & - & - & + grn & - & - & - & - & ++++ & ++++ & - & - & - & - & - \\
\hline 15 & - & - & - & - & - & - & - & - & - & - & - & - & - & - \\
\hline 16 & - & + & - & - & - & - & - & - & - & - & - & - & - & - \\
\hline 17 & - & - & - & - & - & - & - & - & - & - & - & - & - & - \\
\hline 18 & - & - & - & - & - & - & - & - & - & - & - & - & - & - \\
\hline 19 & $80 \%(+)$ & - & - & - & - & - & - & ++++ & ++++ & - & - & - & - & - \\
\hline 20 & - & + & - & - & - & - & - & - & ++++ & ++++ & - & + & - & +++ \\
\hline
\end{tabular}




\begin{tabular}{|c|c|c|c|c|c|c|c|c|c|c|c|c|c|c|}
\hline & BT549 & T47D & MCF7 & HT29 & MDAMB157 & HBL100 & HS578T & $\mathrm{N} 417$ & SW2 & BEAS2B & ZL5 & ZL34 & U1752 & A125 \\
\hline 21 & - & - & - & $(+)$ & - & - & $(+)$ & +++ & ++ & ++++ & ++++ & ++++ & ++++ & ++++ \\
\hline 22 & - & - & - & - & - & - & - & - & +++ & ++++ & - & ++++ & + & + \\
\hline 23 & - & $(+)$ & +++ & $\begin{array}{l}++/+++ \\
\text { s.c. }\end{array}$ & - & - & - & - & ++++ & ++++ & & & & \\
\hline 24 & - & - & - & - & - & - & - & $++/+++$ & ++++ & - & & & & \\
\hline 25 & - & - & - & - & - & - & - & $(+)$ & ++++ & - & & & & \\
\hline 26 & - & - & - & - & - & - & - & - & $(+)$ & - & & & & \\
\hline 27 & - & $(+)$ & + & - & - & - & - & - & ++++ & ++++ & - & - & $(+)$ & - \\
\hline 28 & - & - & - & - & - & - & - & - & - & +++ & ++++ & ++++ & - & - \\
\hline 29 & - & - & - & - & - & - & - & ++++ & ++++ & - & & & . & . \\
\hline 30 & - & - & +++ & ++ & - & - & - & ++++ & ++++ & ++++ & $(+)$ & +++ & - & - \\
\hline 31 & - & +++ & + & - & - & - & - & - & ++++ & - & - & - & - & - \\
\hline 32 & - & - & - & - & - & - & - & ++++ & ++++ & - & - & - & - & - \\
\hline 33 & - & - & - & - & - & - & - & - & - & - & - & - & - & - \\
\hline 34 & $(+)$ & - & - & - & - & - & - & - & - & - & - & - & - & - \\
\hline 35 & $\begin{array}{l}40 \%+ \\
\text { rest (+) }\end{array}$ & +++ & +++ & $(+) /++$ & - & - & - & - & - & + & - & +++ & ++ & ++ \\
\hline 36 & $\begin{array}{l}40 \%+ \\
\text { rest (+) }\end{array}$ & + & + & - & - & - & - & - & - & ++++ & - & - & - & - \\
\hline 37 & - & - & - & - & - & - & - & $(+)$ & - & - & - & - & - & - \\
\hline 38 & - & $(+)$ & - & - & - & - & - & - & - & - & . & 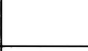 & 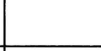 & 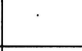 \\
\hline 39 & - & - & - & - & - & - & - & - & - & - & - & - & - & - \\
\hline
\end{tabular}




\begin{tabular}{|c|c|c|c|c|c|c|c|c|c|c|c|c|c|c|}
\hline & BT549 & T47D & MCF7 & HT29 & MDAMB 157 & HBL100 & HS578T & $\mathrm{N} 417$ & SW2 & BEAS2B & ZL5 & ZL34 & U1752 & $\mathrm{A} 125$ \\
\hline 40 & - & - & - & - & - & - & - & $(+)$ & - & - & - & - & - & - \\
\hline 41 & $\begin{array}{l}40 \%+ \\
60 \%(+)\end{array}$ & - & - & - & - & - & - & & - & ++ & ++++ & ++++ & & \\
\hline 42 & - & $(+)$ & + & ++ & - & - & - & + & $(+)$ & ++++ & +++ & ++++ & ++++ & ++++ \\
\hline 43 & - & $(+)$ & $+\mathrm{rim}$ & - & - & - & - & - & ++++ & - & - & - & - & - \\
\hline 44 & $\begin{array}{l}10 \%+ \\
90 \%(+)\end{array}$ & + & +++ & $\begin{array}{l}\text { some } \\
++/+++\end{array}$ & - & - & - & $(+)$ & ++++ & + & $(+)$ & +++ & +++ & +++ \\
\hline 45 & $\begin{array}{l}20 \%+ \\
80 \%(+)\end{array}$ & +++ & $\begin{array}{l}\text { up to } \\
+++\end{array}$ & - & - & - & - & - & - & - & - & - & - & - \\
\hline 46 & - & - & + & - & - & - & - & - & - & - & - & - & - & - \\
\hline 47 & - & - & + & - & - & - & - & - & - & - & - & - & - & - \\
\hline 48 & - & - & - & - & - & - & + grn & - & ++++ & - & ++++ & ++++ & - & ++++ \\
\hline 49 & - & - & - & - & - & - & - & & & & & & & \\
\hline 50 & $\begin{array}{l}80 \%++ \\
20 \%+\end{array}$ & +++ & + & some + & - & - & $(+)$ & $(+)$ & ++++ & ++ & $(+)$ & +++ & +++ & ++++ \\
\hline 51 & - & - & + & - & - & - & - & - & ++++ & ++++ & - & - & - & +++ \\
\hline 52 & - & - & - & - & - & - & - & - & - & - & - & - & - & - \\
\hline 53 & - & - & - & - & - & - & - & - & - & - & - & - & - & - \\
\hline 54 & - & - & ++ grn & + grn & - & - & - & - & - & - & - & - & - & - \\
\hline 55 & - & - & - & + & - & - & - & $(+)$ & - & - & - & - & - & - \\
\hline 56 & - & - & + & - & - & - & - & - & - & - & - & - & - & - \\
\hline 57 & - & - & - & - & - & - & - & - & - & ++++ & - & - & - & $(+)$ \\
\hline
\end{tabular}




\begin{tabular}{|c|c|c|c|c|c|c|c|c|c|c|c|c|c|c|}
\hline & BT549 & T47D & MCF7 & HT29 & MDAMB157 & HBL100 & HS578T & $\mathrm{N} 417$ & SW2 & BEAS2B & ZL5 & ZL34 & U1752 & A125 \\
\hline 58 & - & - & - & - & - & - & - & $(+)$ & - & - & & & & \\
\hline 59 & + & - & - & - & - & + grn & - & $(+)$ & ++++ & ++++ & - & +++ & +++ & ++++ \\
\hline 60 & - & - & - & $(+)$ & - & - & - & - & - & - & - & - & - & - \\
\hline 61 & - & - & - & - & - & - & - & - & - & - & - & - & - & - \\
\hline 62 & - & +++ & $(+)$ & $5 \%+++$ & + s.c. & + & - & ++++ & +++ & $(+)$ & - & + & +++ & ++++ \\
\hline 63 & - & - & - & - & - & - & - & $(+)$ & +++ & ++++ & - & +++ & ++ & ++++ \\
\hline 64 & - & - & - & - & - & - & - & - & - & - & & & & \\
\hline 65 & - & - & - & - & - & - & - & ++++ & + & - & & & & \\
\hline 66 & - & + & - & - & - & $(+)$ & - & ++++ & $+/++$ & + & - & - & & - \\
\hline 67 & - & - & - & - & - & - & - & - & - & - & - & - & - & - \\
\hline 68 & - & - & - & - & - & - & - & - & - & - & - & - & - & - \\
\hline 69 & - & - & - & - & - & - & - & & & & & & & \\
\hline 70 & - & $(+)$ & - & - & - & - & - & & & & & & & \\
\hline 71 & + & + & ++ & - & - & - & - & $+/++$ & ++++ & +++ & - & ++++ & ++++ & ++++ \\
\hline 72 & - & $(+)$ & - & - & - & - & - & - & $(+)$ & + & + & ++++ & +++ & ++++ \\
\hline
\end{tabular}

c.m. cell membrane reactivity.

grn granular fluorescence.

s.c. $\quad$ single cells reacted.

Note: The term clones indicates the reactivity of multiple groups of cells reacting with the antibody; these groups are generally surrounded by non-reacting cells. Single cell reactivity indicates the reactivity of few individual cells reacting with the antibodies, granular fluorescence indicates the reactivity of presumably intracellular granules with the antibodies while the terms rim and cell membranes indicate a reactivity which is confined to the cell membrane and its immediate surroundings such as the extracellular matrix. The differentiation between cell membrane and extracellular membrane reactivity cannot be resolved at the light microscopical level for epithelial cells as the extracellular space is so small. 
Fig. 2a

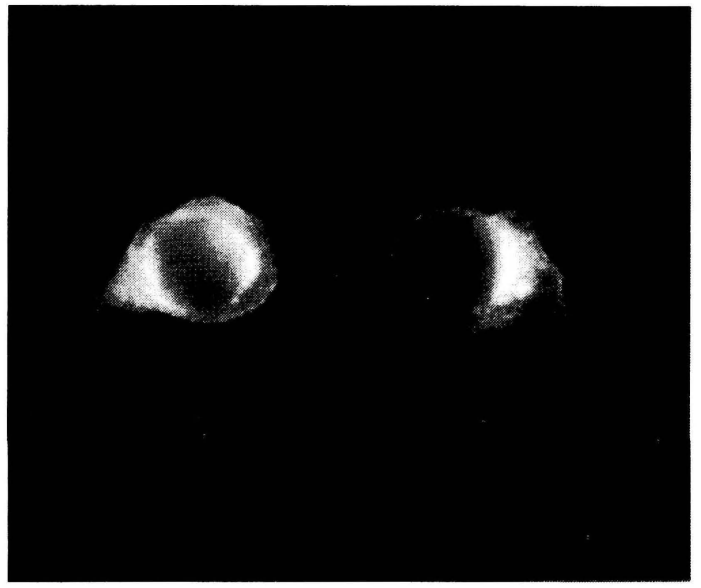

Fig. $2 b$

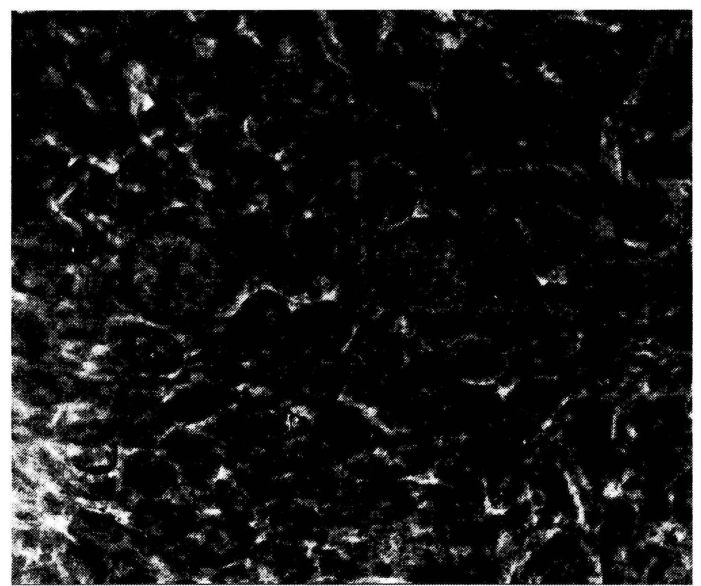

Fig. 2c

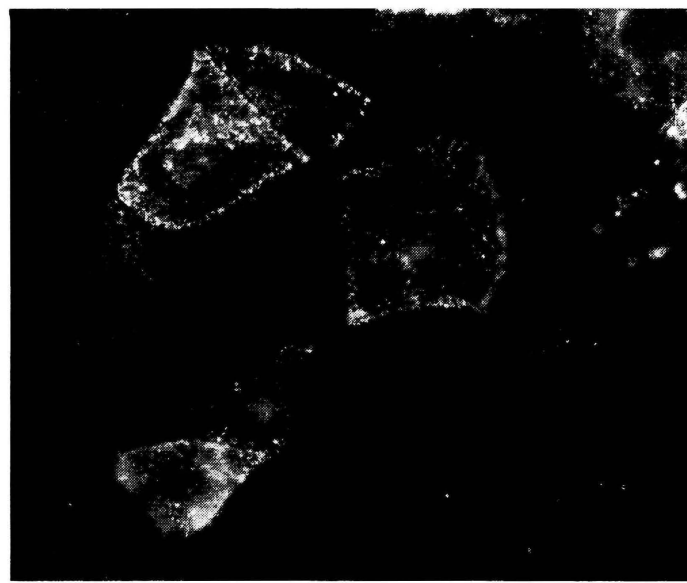

Figure 2. Photomicrographs of cultured (a) HT29 colon cancer cell line and (c) MC7 breast cancer cell line showing some FITC labelled cells after reactivity with the antibody number 23 (MLuC-1) and the antibody number 54 (1.291) respectively. b) is a phase contrast photomicrograph of the same labelled cells in Fig. (a). $\mathrm{X} 415$. 


\section{DISCUSSION}

The present study has shown that monoclonal antibodies designed for detecting oncodevelopmental antigens expressed in lung cancer can also share epitopes of breast and colon cancer cell lines. Furthermore a heterogeneity of the antibody binding towards the different breast cancer cell lines has been observed indicating a phenotypical diversity of these cell lines. Some of the many cross reactivities of the antibodies with the breast and colon cancer cell lines seem to be of functional interest which might have implications concerning the prognosis of both breast and lung cancer:

1) The antibodies no 24-26 directed against the neuronal cell adhesion molecule (NCAM) immunoreacted only with the two cell lines derived from small cell carcinoma of the lung, while other antibodies with NCAM specificity showed a broader reactivity: antibody 4 reacted with the mesothelioma derived cell line ZL 34 and with the breast cancer cell line BT 549, antibody no 14 with the breast cancer cell line MCF7 and antibody no 19 with the breast cancer cell line BT549. At the moment it is not clear whether these are indeed different epitopes of the NCAM molecule recognised by the different antibodies, or whether they are cross reactivities with epitopes other than NCAM. Since neuroendocrine markers can be expressed by breast cancer (for review see Nesland et al., 1988) NCAM expression on these breast cancer derived cells is likely.

2) The antibody no 72 directed against a mucin antigen cross reacted with all lung cancer cell lines except the mesothelioma derived cell line ZL5 and with the breast cancer derived cell lines BT549, T47D and MCF7. Common expression of mucin antigens in normal and pathological conditions of lung and breast tissue is well known (Welsch et al., 1990, Spicer et al., 1991, Pemberton et al., 1992) and this reactivity is therefore not unexpected.

3) The mesothelioma specific antibody no 41 showed its strongest reactivity with the mesothelioma derived cell lines ZL5 and ZL34; in addition it reacted with the immortalised human bronchial-derived cell line BEAS-2B and the breast cancer cell line BT549, the nature of this binding pattern being obscure at present.

4) The distribution of cell surface receptors which react with the extracellular matrix differs. In addition to reactivity with various lung cancer derived cell lines, laminin receptor immunoreactivity was detected on the breast derived cell lines T47D (antibody no 20) and BT549 and HBL100 (antibody no 59). The immunoreactivity of this receptor seems to be more widespread than that for beta-1-integrin antibodies detected in HS578T and HT29 (antibody 21). Alpha-6-integrin was detected on lung derived cell lines only (antibody no 22). The biological implications of these findings are not clear at present, but the interaction of these receptors with their ligand(s) in the extracellular matrix seems to play a crucial role within the metastatic cascade (Hart and Saini, 1992).

Our findings therefore indicate that several antigens thought to be lung cancer specific can also be expressed on breast and colon cancer cell lines. Any claims towards specificity of many of those antibodies therefore have to be treated with great care.

\section{REFERENCES}

Braga, V.M.A., Pemberton, L.F., Duhig, T., Gendler, S.J. (1992). Spatial and temporal expression of an epithelial mucin, Muc-1, during mouse development. Development, 115, 427-437.

Hart, I.R., Saini, A. (1992). Biology of tumour metastasis. Lancet, 339, 1453-1461. 
Nesland, J.L., Holm, R., Johannesen, J.V., Gould, V.E. (1988). Neuroendocrine differentiation in breast lesions. Path. Res. Pract., 183, 214-221.

Pemberton, L., Taylor-Papadimitriou, J., Gendler, S.J. (1992). Antibodies to the cytoplasmic domain of the MUC1 mucin show conservation throughout mammals. Biochem. Biophys. Res. Comm., 185, 167-175.

Schumacher, U., Barth, J., Petermann, W., Welsch, U., Patton, St. (1987). Detection of high molecular weight glycoproteins in the broncho-alveolar lavage fluid by gel electrophoresis. Am. Rev. Respir. Dis., 135, A505.

Spicer, A. P., Parry, G., Patton, S., Gendler, S. J. (1991). Molecular cloning and analysis of the mouse homologue of the tumor-associated mucin, MUC1, reveals conservation of potential Oglycosylation sites, transmembrane, and cytoplasmic domains and a loss of minisatellite-like polymorphism. J. Biol. Chem., 266, 15099-15109.

Welsch, U., Schumacher, U., Buchheim, W., Schinko, I., Jenness, P., Patton, S. (1990). Histochemical and biochemical observations on milk-fat-globule membranes from several mammalian species. Acta histochem. Suppl. XL, 59-64. 


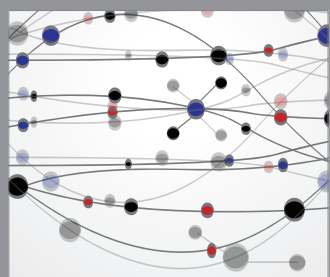

The Scientific World Journal
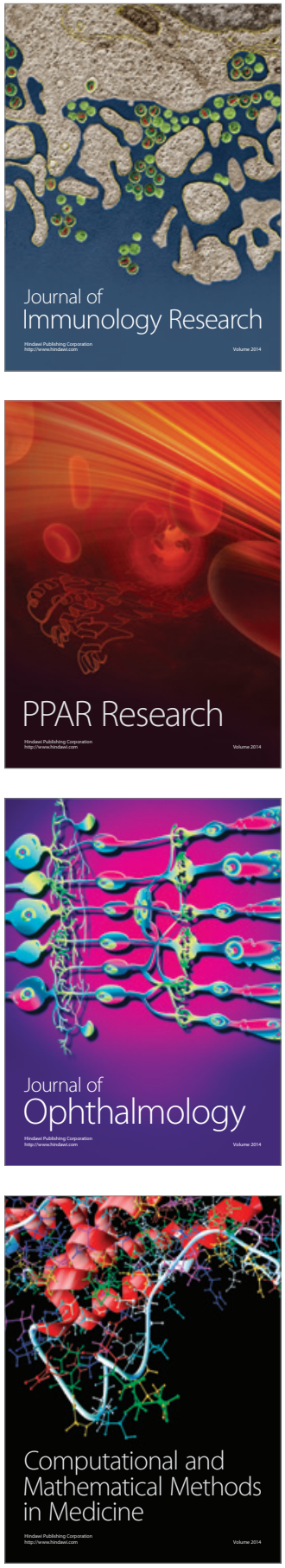

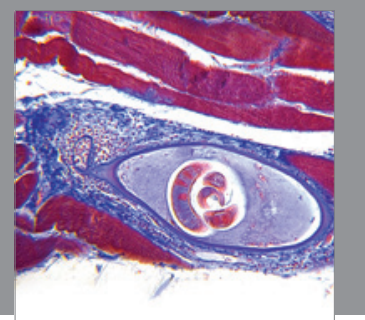

Gastroenterology

Research and Practice
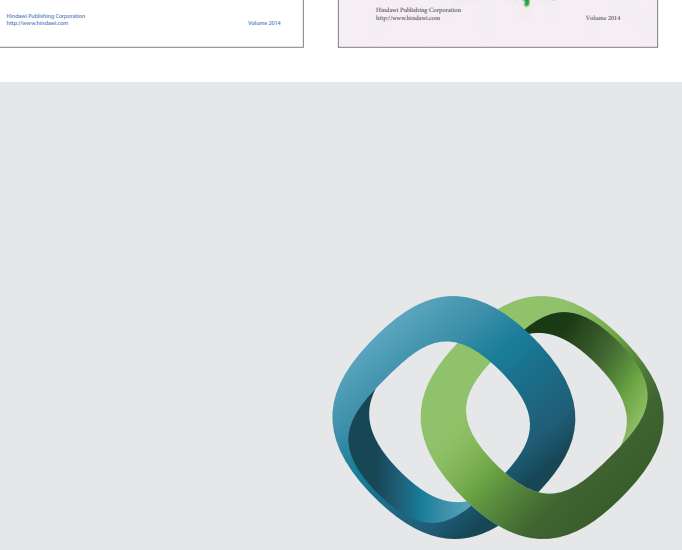

\section{Hindawi}

Submit your manuscripts at

http://www.hindawi.com


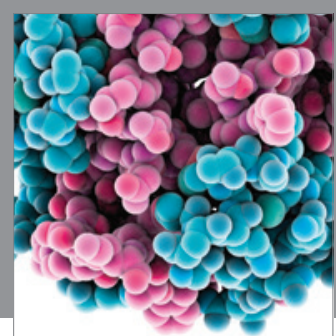

Journal of
Diabetes Research

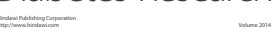

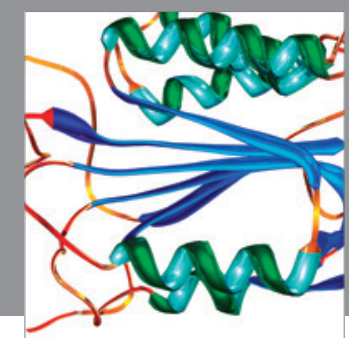

Disease Markers
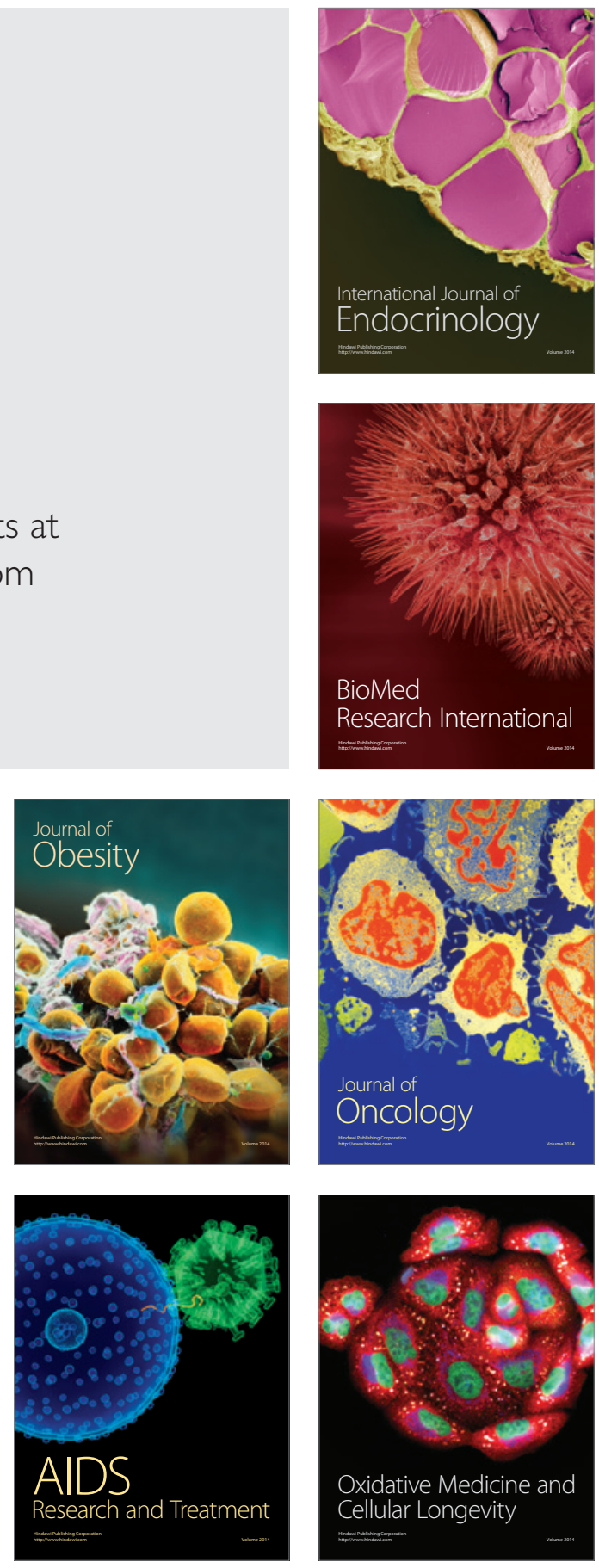